\title{
BIBLIOGRAPHIE.
}

[1] J. Sснмптт. Traité de chimie organique (traduction), Albin Michel, éd., 1928.

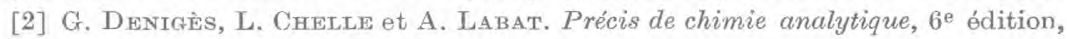
Maloine, éd., Paris, 1930.

[3] M. Schons. Problèmes de spécificité dans les processus de fermentation. Annales de l'Institut Pasteur, décembre 1931.

[4] N. King. L'action du diacétyle sur la matière grasse du heurre. Milchwirtschaftliche Forschungen, 29 mai 1931, 12, 172 et suivantes.

[5] C. Schmeidler. Recherches récentes sur l'arome du beurre. An. in Chimie et Industrie, septembre 1930, 24, 3.

[6] G. Testoni et W. Cuusa. Détermination du diacétyle dans le beurre. Ann. chim. applicata, 1931, 21, 147-150.

[7] H. Lemorgne. Assimilation du saccharose par les bactéries du groupe du B. subtitis. Fermentation butylène-glycolique. Annalss de l'Institut Pasteur, 27, 856.

[8] C. Neuberg et MHe Kobet. Die desmolytische Bildung von Methyglyoxal durch Hefenenzym. Biochem. Zeitschr., 1928, 203, 463.

[9] C. Neubfrg et E. Reinfurth. Eine Neue form der Umwandlung des Acetaldehyds durch gärende Hefe. Biochem. Zeitschr., 1923, 143, 553.

[10] Van Nrer, KuUyver et Dere. Biochem. Zeitschr., 1929, 210, 234.

[11] Schmalfuss et Barthmeyer. Biochem. Zeitschr., 1929, 216, 330.

\section{EXAMEN BACTÉRIOLOGIQUE DES BEURRES (1)}

\section{par \\ F. DIÉNERT.}

La fièvre typhoïde est une maladie dont l'origine est le plus souvent attribuée à l'eau consommée. C'est en se basant sur cette étiologie qu'on a amélioré considérablement la nature des eaux distribuées dans la plupart des villes et, dans ces dernières années, dans un grand nombre de villages.

La composition bactériologique des eaux potables ne doit pas renfermer certains germes pathogènes ou suspects. Le $B$. Coli communis, hôte habituel de l'intestin des animaux et des hommes, doit être absent de ces eaux.

D'autres causes étiologiques ont été ajoutées à l'eau d'alimentation, en particulier les huîtres et les coquillages, les salades, le lait, les fromages blanes, le contact direct.

Depuis la guerre, la surveillance hygiénique des huîtres a été officiellement organisée et semble donner des résultats intéressants. On s'efforce d'obtenir des produits exempts de $B$. Coli communis.

La surveillance des coquillages est plus difficile à organiser. On se heurte à des intérêts multiples, moins groupés que pour les huîtres.

(1) Bulletin de l'Académie de Médecine, séanco du 19 juillet 1932. 
La composition bactériologique des coquillages laisse souvent à désirer et dans certains centres méridionaux on attribue $40 \%$ des cas de fièvre typhoïde à la consommation de ces produits.

Les salades sont obtenues sur des terrains fortement fumés. Sur le marché, elles sont vendues souillées de terre et apportent avec elles du B. Coli. Avant leur consommation, on lave les feuilles de salade dans l'eau, et les analyses que j'ai faites avec M. ETrILLARD, mon collaborateur, ont montré que le nombre des germes du genre $B$. Coli absorbés par le consommateur de salade est faible si le lavage est convenablement fait. Souvent on atténue le mauvais lavage par un apport important de vinaigre, dont l'effet antiseptique sur le $B$. Coli communis est connu.

Le lâit a donné lieu à quelques épidémies de fièvre typhoïde, dues surtout à sa manutention par un porteur de germes ou par l'usage d'eaux malsaines pour le nettoyage des récipients. J'ai eu à signaler, il y a 25 ans, une épidémie de ce genre dans les environs de Sens. Le lait est consommé très souvent bouilli, et, dans ce cas, le $B$. Coli est tué.

On a signalé récemment que les fromages blancs et frais peuvent propager la fièvre typhoïde. Ils renferment du $B$. Coli, mais le développement des ferments lactiques étouffe ce germe. Il y a là cependant un danger certain et une cause d'infection.

Les porteurs de germes ont fait l'objet, avant la guerre, d'une étude épidémiologique très complète par l'école bactériologique allemande et je n'insisterai pas plus longuement sur eux.

Mon attention a été appelée dernièrement sur l'intervention possible du beurre dans l'étiologie de la fièvre typhoïde. J'ai constaté certains cas coïncidant avec la consommation de beurres venant de régions où régnaient de nombreux cas de fièvre typhoïde.

J'ai été ainsi amené à faire une étude bactériologique d'une certaine quantité de beurres provenant de différentes régions. J'ai été intelligemment aidé dans cette tâche par mes deux collaborateurs : MM. Etrilllard et Malherbe.

Nous avons dosé l'acidité des beurres examinés et nous l'avons exprimée en acide sulfurique $\left(\mathrm{SO}^{3}\right)$.

Nous avons recherché le $B$. Coli, le proteus, le Para B., le B. d'Eberth.

Nous avons procédé de la façon suivante : le beurre (10 gr.) était fondu en présence de $100 \mathrm{~cm}^{3}$ d'eau stérile et fortement émulsionné avec cette dernière. On laissait ensuite le beurre se rassembler en surface, et c'est sur l'eau de lavage que nous recherchions les bactéries suspectes.

Cette étude a été poursuivie avec la collaboration attentive du Syndicat des mandataires aux Halles, qui nous a donné toutes 
facilités pour faire des prélèvements sur les beurres de toutes les provenances. On nous permettra de ne pas indiquer les origines de ces beurres, que nous désignerons simplement par des numéros.

Les résultats sont indiqués dans le tableau ci-après :

\begin{tabular}{|c|c|c|c|c|c|}
\hline $\begin{array}{c}\text { Numéro } \\
\text { du } \\
\text { beurre }\end{array}$ & $\begin{array}{c}\text { Acidité en } \mathrm{SO}^{3} \\
\text { dans } 100 \mathrm{gr} . \\
\text { de beurre } \\
\text { Gr. }\end{array}$ & $\begin{array}{c}\text { B. Coli } \\
\text { dans } 100 \text { gr. } \\
\text { de beurre }\end{array}$ & B. d'Eberth. & B. Para B & Observations \\
\hline 1 & 0,088 & 40.000 & 一 & 一 & \\
\hline 2 & $0,1,00$ & 10.260 & 一 & - & \\
\hline 3 & 0,060 & 1600 & 一 & + & \\
\hline 4 & 0,053 & 1.923 .000 & + & - & \\
\hline 5 & 0,074 & 125.000 & - & - & \\
\hline 6 & 0063 & 12.200 & - & + & \\
\hline 7 & 0,084 & 3.600 & - & 一 & \\
\hline 8 & 0,084 & 117.857 & + & - & \\
\hline 9 & 0,061 & 20.000 & - & + & \\
\hline 10 & 0,136 & 0 & + & - & - \\
\hline 11 & 0,096 & 400 & 一 & 一 & \\
\hline 12 & 0,063 & 600 & 一 & - & \\
\hline 13 & 0,140 & 0 & 一 & 一 & \\
\hline 14 & $0, \mathbf{1 2 0}$ & 0 & 一 & 一 & \\
\hline 15 & 0,080 & 0 & - & 一 & Beurre falsifié \\
\hline 16 & 0,080 & 348.000 & - & 一 & \\
\hline 17 & 0,060 & 2.600 .000 & 一 & 一 & \\
\hline 18 & 0,045 & 1.333 .000 & - & - & \\
\hline 19 & 0,055 & 857.000 & - & - & \\
\hline
\end{tabular}

L'examen de ces résultats montre que plus le beurre est acide, moins il y a de $B$. Coli ou autres colonies suspectes. C'est un moyen naturel de purification bactériologique.

Certains beurres ont une richesse excessive en B. Coli. En consommant $10 \mathrm{gr}$. de beurre, on absorbe certainement plus de $B$. Coli qu'en mangeant trois salades mal lavées ou une douzaine d'huîtres.

Deux beurres renfermaient du B. d'Eberth nettement caractérisé : les beurres 4 et 8 . Le beurre 10 donnait un germe ayant certains caractères du B. d'Eberth; en particulier, il donnait lieu à une agglutination partielle.

Le beurre 3 renfermait nettement du B. Paratyphique B. Les germes des beurres 6 et 9 agglutinaient au sérum para B mais donnaient de l'indol.

Certains germes de $B$. Coli noircissaient sur la gélose au plomb, 
comme très souvent lorsqu'ils proviennent d'un intestin où l'on trouve du B. d'Eberth ou du Para B.

Les mandataires aux Halles ont remarqué depuis longtemps que les beurres centrifugés de certaines laiteries ne se conservaient pas. Cependant, ees établissements ont fait quelquefois des dépenses considérables pour s'approvisionner en eau par forages profonds. Malheureusement, la profondeur ne signifie rien si le terrain est calcaire et perméable avec, aux environs, des absorptions d'eaux usées.

En communiquant ces résultats, j'attire tout particulièrement l'attention sur la mauvaise qualité bactériologique de certains beurres et j'émets le vœu qu'une étude sur place puisse permettre d'envisager les moyens d'améliorer celle-ci. Il y a là une cause nouvelle d'étiologie de la fièvre typhoïde qu'il est indispensable de supprimer, parce que la consommation du beurre cru est très répandue.

\title{
SUR LA RECHERCHE DU BACTERIUM COLI DANS LE LAIT
}

\author{
JEAN PIEN \\ Ingénieur chimiste (I. C. R.) \\ Docteur ès Sciences \\ Directeur des Laboratoires \\ des "Fermiers Réunis "
}

par
et JACQUES BACHIMONT
du Laboratoire de Bactériologie des "Fermiers Réunis"

\section{(Suite).}

\section{DEUXIÈME ARTICLE.}

Dans notre précédent article sur cette question nous croyons avoir montré l'intérêt qui s'attache à la recherche du $B$. Coli dans le lait (raisons d'ordre hygiénique et d'ordre industriel). Nous avons insisté également sur la nécessité, surtout dans le contrôle industriel, d'effectuer cette recherche sur des quantités de lait bien supérieures à $1 \mathrm{~cm}^{3}$, puisque, dans ce dernier eas, le résultat est limité à 1.000 germes au litre, alórs qu'il y a souvent intérêt (dans l'industrie surtout) à déceler de plus faibles quantités de colibacilles. C'est ainsi qu'on peut même être amené à rechercher si un lait contient moins de 50, moins de 20 germes de $B$. coli au litre. La nécessité d'opérer sur d'assez grands volumes de lait pour déceler de petites quantités de coli nous paraît évidente (1).

(1) L'ingénieuse méthode de Mac Crady [1], qui consiste à opérer sur de petite volumes à l'aide d'un certain nombre de tubes en séries parallèles de dilutions différentes et à interpréter les résultats en s'aidant d'une formule mathématique, doit être à notre avis réservée aux teneurs élevées en colibacilles et ne semble pas applicable ici. 